\title{
Attitudes towards Inclusion of Sustainability Characteristics within New Zealand's Eating and Activity Guidelines by Professionals in the Agriculture, Environment and Health Sectors ${ }^{\dagger}$
}

\author{
Rebekah Jones ${ }^{1}$, Barbara Burlingame ${ }^{2}$ and Carol Wham 1,* \\ 1 School of Sport, Exercise and Nutrition, Massey University, Auckland 0745, New Zealand; \\ R.Jones@massey.ac.nz \\ 2 School of Health Sciences, Massey University, Wellington 6140, New Zealand; \\ barbara.burlingame@gmail.com \\ * Correspondence: C.A.Wham@massey.ac.nz \\ + Presented at the 2018 Nutrition Society of New Zealand Annual Conference, Auckland, New Zealand, \\ 28-30 November 2018.
}

Published: 13 March 2019

Background: Globally, adverse health and environmental changes are occurring associated with changes in the food and nutrition system. The FAO has called for sustainable diets which are "protective of biodiversity and ecosystems, culturally acceptable, accessible, affordable, nutritionally adequate, safe and healthy; while optimising natural and human resources". The inclusion of sustainability characteristics in New Zealand's Eating and Activity Guidelines (EAGs) has become compelling. This study aimed to evaluate the agreement for inclusion of sustainability characteristics within the guidelines among sectoral professionals.

Methods: Agriculture, environment and health sector professionals were invited to complete an online survey to establish agreement to sustainability characteristics using a 20 item Likert scale. Participant gender, age and education level were determined.

Results: Overall, 298 (65\% female) respondents completed the survey (37\%, $22 \%$ and $41 \%$ from the agriculture, environment and health sectors respectively). Two thirds (66\%) of respondents were over 35 years and $90 \%$ had a tertiary education. Most (76\%) respondents disagreed New Zealand's current food system is sustainable; health $(77 \%)$, environment $(78 \%)$ sectors had greater disagreement than agriculture $(35 \%)(p \leq 0.001) .73 \%$ of respondents agreed that sustainability characteristics should be included in the guidelines; health $(90 \%)$ and environment $(84 \%)$ sectors agreed more than agriculture $(48.2 \%)(p \leq 0.001)$. Most respondents tended to agree with the inclusion of the 15 individual sustainability characteristics in the guidelines except "Purchase and support for organic food produce" was low (35\%). Agreement for nine sustainability characteristics was higher among the health and environment sectors versus the agricultural sector $(p<0.05)$ whereas sector agreement for "diet diversity", "recommended serves of dairy products", "sustainable seafood consumption", "reduction of food waste" and "sustainable lifestyle behaviours" was unanimous ( $p>0.05)$.

Conclusion: Professionals from the agriculture, environment and health sectors largely support the inclusion of sustainability characteristics in the New Zealand's EAGs. 